\title{
Construction and Optimization of Reverse Logistics Network of Home Appliance
}

\section{Products}

\author{
Xueyuan Wang, Yifei Geng, Zhining Zhang \\ School of Management Engineering, Zhengzhou University, Zhengzhou 450001, China
}

Keywords: green logistics, reverse logistics network, lingo analysis, optimization model

\begin{abstract}
With the development of China's low carbon economy and green logistics, the optimization design of reverse logistics network is studied in depth with the reverse logistics cost as the performance evaluation index. By understanding the basic content of reverse logistics network, the paper discusses the electrical appliances product reverse logistics network optimization model of the problem, finally, through a lingo example analysis, it understands the process of construction of reverse logistics network, which has a good reference value.

\section{INTRODUCTION}

In the past decade, rapid economic development and

between the nodes and nodes of reverse logistics (Hongxia Chen, Chao Liu,2015). In modern times, the reverse logistics network information system is introduced to connect the various logistics nodes.
\end{abstract} improve the level of consumption, make electrical appliances product is no longer ordinary people in the eyes of luxury, more and more families began a large number of consumer appliances (Mengting Wu,2015). Meanwhile, the heat of China's real estate market has led to the consumption of the household appliance market, and the update of home appliance products is getting faster and faster. These factors make the production of Chinese household appliances more and more each day, the return of goods of home appliance product, the return of unqualified product, the newspaper waste also gradually increases (Xiaobing Xu,2013). According to statistics, in 2014 China's electrical appliances product scale up to 984.749 billion, mainly household appliances products including computers, refrigerators, washing machines, TV sets, air conditioners, scrap amount each year more than 200 million units, the data is growing at the speed of fast, every year over the next ten years is expected to reach more than 500 million units a year. However, in our country, the reverse logistics of consumer and enterprise appliance products, so casually discard the phenomenon of waste household appliances. Especially in some remote parts of the geographical position, the high cost of reverse logistics network channel does not conform to the actual situation, therefore, the construction of electrical appliances product reverse logistics network is still a long way to go (Longqing Liu, Guoqing Zhang, 2013).

\section{BASIC UNDERSTANDING OF REVERSE LOGISTICS NETWORK}

\subsection{Reverse logistics network definition}

Reverse logistics network is refers to the reverse logistics system in the logistics node (mainly include collection, recycling center, processing center, warehouse, distribution market, and waste disposal configuration, and the arrangement of the transport routes, etc. The essence is the structure network of the transport route

\subsection{Reverse logistics network classification}

Classification is also different. Common classification methods include:

(1) according to three reprocessing methods, it can be divided into reverse logistics network, reverse logistics network and reverse logistics network;

(2) the reverse driving factors can be divided into government-led reverse logistics network, economic efficiency reverse logistics network, public welfare organization reverse logistics network, etc.

\subsection{The structural characteristics of reverse logistics network}

Due to different structural features and functions, the following indicators of structural characteristics are formed:

(1) concentration, representing the extent of reverse logistics network, represents the number of locations of the same work process, which can be considered as the number of nodes of the same type;

(2) the degree of network opening is divided into open-loop and closed-loop reverse logistics network;

(3) network correlation degree, the reverse logistics network has some independent and some extension of the original logistics network;

(4) network layer number, which represents the vertical depth of reverse network;

(5) type of inter-organizational cooperation, the most common outsourcing model.

\subsection{The function of reverse logistics network}

Different reverse logistics network, its design is not the same, but the basic process is to convert waste products to have economic value of goods, distribution to the market, its main function is the same, as long as the collection, classification, including product testing, storage, transportation, recycling, remanufacturing, recycling, waste treatment, and distribution, etc (Rajesh Piplani, Ashish Saraswat,2012). 


\subsection{The goal of reverse logistics network}

It is in the circumstance that the law and regulation permits, considering customer service and realizing the regeneration of product economic value with the lowest cost or the highest benefit, realize the optimization of resources (Alessandro Creazza, Fabrizio Dallari, T ommaso Rossi, 2012).

\section{REVERSE LOGISTICS NETWORK PLANNING PROBLEMS AND METHODS}

\subsection{Reverse logistics network planning problem}

Similar to the forward logistics network, the reverse logistics network planning should consider the planning of both time and space (Ji Hu, 2014). According to the process, the following aspects are mainly included:

(1) the function design of the facilities in reverse logistics network shall be analyzed from the process link of the whole network to clarify the establishment of hardware and software systems in the system network;

(2) the layout planning of the various facilities in the network, the actual location of the facility is the problem, and the location of each node should be clearly defined;

(3) determine the size of each facility in the network, including the scale and efficiency of the set at the same time, the reasonable standard is not only ensure network normal operation, and can't afford to waste the resources available, cause waste;

(4) market and supply configuration, on the one hand, to understand the supply of the reverse logistics network products, namely the supply of waste products, on the other hand to reasonable distribution of good work, both to ensure facilities can include all scattered market demand, and can guarantee the supply of goods meet the processing capacity of facilities, to optimize the route to reduce the cost.

\subsection{Overview of the method of reverse logistics network planning}

Reverse logistics network planning is to establish reverse logistics system to solve the first one of the most basic and most important problems, the product variety, reverse network composition complex, facilities planning problem, the logistics cost, the difficulty is imaginable (Xiaoyong Pan, Jiang Wu, Yong Liu,2013).

The focus of reverse logistics network planning includes site selection, route design, vehicle scheduling, etc. The most common method is to build. In order to simplify the occurrence of all kinds of complex and random situations in the network, we can make the deterministic approximation and obtain a controllable mathematical model, and finally analyze and obtain the optimal solution (Zhe Luo,Yunli Liu,Youdi Su,2013). Mathematical models can give us a clearer idea of how to solve problems. Modern modern computer applications make these mathematical models easier, and only with professional software such as lingo can quickly produce optimal results.

\section{CONSTRUCTION AND OPTIMIZATION OF REVERSE LOGISTICS NETWORK OF HOME APPLIANCE PRODUCTS}

\subsection{Construction of network process design of reverse logistics network of home appliances products}

Independent household appliance products reverse logistics network without external interference factor intervention, the process is relatively simple, relatively single, processing efficiency is high. The basic process includes the following steps: the product is collected at the source point and transported to the recycling center; The recycling center is simple to handle, detect and classify and send to reprocessing center; The reprocessing center is examined by the system, and it is disassembled and repaired. The processed products can be resold, remanufactured and recycled into the distribution market depending on the nature of the product. Its simple flow chart is as follows:

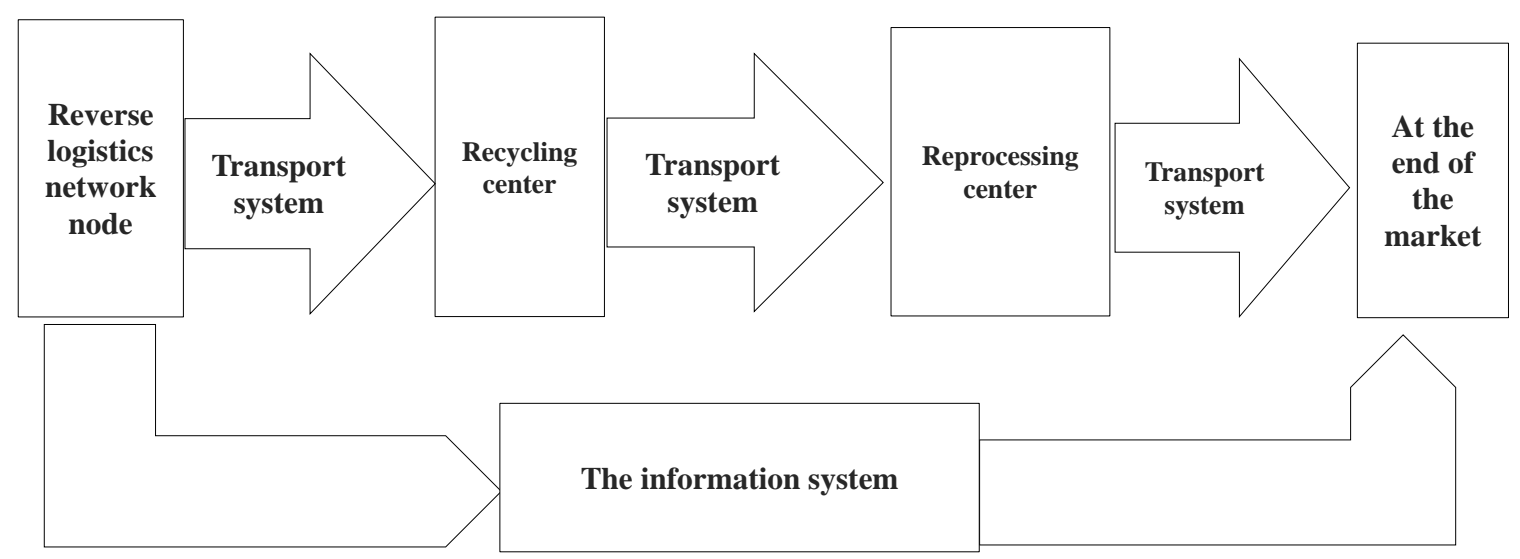

FIG. 1 Flowchart of reverse logistics network of household appliances

\subsection{Optimization model of reverse logistics network for home appliance products}

\subsubsection{Problem hypothesis}

The model established in this paper mainly considers the relative independent reverse logistics network system, and there is no correlation between forward logistics (Min He, Meiling Deng,2016).

(1) the reverse logistics network, starting from an independent point of view, does not have the influence of time, and only considers the macro influence factors in the period; 
(2) the source points of the logistics network are determined. The location and number of location of the recycling center and reprocessing center are determined. The cost of construction is known and the processing capacity of the reprocessing center is known (Lin Liu,2012);

(3) the cost of the reverse logistics network transportation system is related to the freight volume, unit transport cost and the transport mileage, and the transport is one-way, without considering the return trip;

(4) The flow of waste household appliances is a one-way, from the source point to the recycling center, the reverse logistics network to the processing center, to the end of the market, and waste products before entered again processing center, attribute as its unit, terminal market not clear not to consider;

(5) government subsidies are fixed values related to unit attributes and are related to household appliances;

(6) the inventory quantity of the reverse logistics network source points is large enough, without considering the empty load, the number of vehicles is not considered, and the purchase of the vehicle is included in the transportation cost;

(7) replace a wide variety of household appliance products with large volumes of computers, refrigerators, washing machines, televisions and air conditioners.

\subsubsection{Model parameters and variables}

I represents the reverse logistics source point,i $\in$ $\{1,2,3 \ldots \mathrm{I}\}$;

$\mathrm{J}$ represents the location of the recycling center,je $\{1,2,3 \ldots J\}$;

$\mathrm{K}$ represents the location of the reprocessing center, $\mathrm{k} \in\{1,2,3 \ldots \mathrm{K}\}$;

$L \in\{1,2,3,4,5\}$ The computer, refrigerator, washing machine, TV set and air conditioner are respectively indicated;

$\mathrm{W}_{\mathrm{j}}=0$ or 1 represents whether to establish a recycling center in the recycling center, 0 for no, 1 for yes;

$\mathrm{W}_{\mathrm{k}}=0$ or 1 represents whether the location of site $\mathrm{k}$ is established in the reprocessing center, 0 for no, 1 for yes;

$\mathrm{R}_{\mathrm{j}}$ represents the construction cost of the recycling center j;

$\mathrm{C}_{\mathrm{I}}^{\mathrm{L}}, \mathrm{C}_{\mathrm{j}}^{\mathrm{L}}, \mathrm{C}_{\mathrm{k}}^{\mathrm{L}}$ represent the appliances in the source point, recycling centers, logistics and processing center, the aerage cost of each unit of work;

$\mathrm{d}_{\mathrm{ij}}$ represents the distance from the reverse logistics source point $\mathrm{I}$ to the recycling center $\mathrm{j}$;

$\mathrm{d}_{\mathrm{jk}}$ means the distance from the recycling center $\mathrm{j}$ to the reprocessing center $\mathrm{k}$;

$\mathrm{p}_{\mathrm{ij}}^{\mathrm{L}}$ represents the unit freight of the product $\mathrm{L}$ from the reverse logistics source point I to the recycling center $\mathrm{j}$;

$\mathrm{p}_{\mathrm{jk}}^{\mathrm{L}}$ represents the unit freight of the home appliance product $\mathrm{L}$ from the recycling center $\mathrm{j}$ to the reprocessing center k;

$\mathrm{Q}_{\mathrm{i}}^{\mathrm{L}}$ Represents the preparation capacity of home appliance product $\mathrm{L}$ in reverse logistics source point I;

$Q_{i j}^{L}$ represents the volume of the product $L$ from the reverse logistics source point I to the recycling center $\mathrm{j}$;

$\mathrm{Q}_{\mathrm{jk}}^{\mathrm{L}}$ represents the product $\mathrm{L}$ from the recycling center $\mathrm{j}$ to the reprocessing center k capacity;

$\mathrm{B}^{\mathrm{L}}$ represents state subsidies for the recycling of household appliances in each unit;

$\mathrm{M}_{\mathrm{k}}^{\mathrm{L}}$ represents the maximum capacity of k processing appliances in the reprocessing center;

\subsubsection{Model establishment.}

(1) The model considers variable costs and state subsidies for design, including construction expenses, operating expenses and transportation expenses. We use G, U, Y and N respectively for construction expenses, operating expenses, transportation expenses, state subsidies.

(1) construction cost is derived from the recycling center and processing center again two parts, as follows:

$$
\mathrm{G}=\sum_{\mathrm{j}=1}^{\mathrm{j}}\left(\mathrm{R}_{\mathrm{j}} * \mathrm{~W}_{\mathrm{j}}\right)+\sum_{\mathrm{k}=1}^{\mathrm{k}}\left(\mathrm{R}_{\mathrm{k}} * \mathrm{~W}_{\mathrm{k}}\right)
$$

(2) operating costs include the reverse logistics network source point, recycling center and processing center operation cost of three parts, as follows:

$$
\begin{array}{r}
\mathrm{U}=\sum_{\mathrm{L}=1}^{\mathrm{L}} \sum_{\mathrm{i}=1}^{\mathrm{I}}\left(\mathrm{C}_{\mathrm{i}}^{\mathrm{L}} * \mathrm{Q}_{\mathrm{i}}^{\mathrm{L}}\right)+\sum_{\mathrm{L}=1}^{\mathrm{L}} \sum_{\mathrm{i}=1}^{\mathrm{I}} \sum_{\mathrm{j}=1}^{\mathrm{J}}\left(\mathrm{C}_{\mathrm{i}}^{\mathrm{L}} * \mathrm{Q}_{\mathrm{ij}}^{\mathrm{L}} *\right. \\
\left.\mathrm{W}_{\mathrm{j}}\right)+\sum_{\mathrm{L}=1}^{\mathrm{L}} \sum_{\mathrm{k}=1}^{\mathrm{I}} \sum_{\mathrm{j}=1}^{\mathrm{J}}\left(\mathrm{C}_{\mathrm{k}}^{\mathrm{L}} * \mathrm{Q}_{\mathrm{jk}}^{\mathrm{L}} * \mathrm{~W}_{\mathrm{k}}\right)
\end{array}
$$

(3)transportation cost of reverse logistics network source points to the recycling center, the recycling centre to the reprocessing center 2 the cost of the process, is proportional to the unit freight, traffic volume, distance, are as follows:

$$
\begin{gathered}
\mathrm{Y}=\sum_{\mathrm{L}=1}^{\mathrm{L}} \sum_{\mathrm{i}=1}^{\mathrm{I}} \sum_{\mathrm{j}=1}^{\mathrm{J}}\left(\mathrm{P}_{\mathrm{ij}}^{\mathrm{L}} * \mathrm{Q}_{\mathrm{ij}}^{\mathrm{L}} * \mathrm{~d}_{\mathrm{ij}} * \mathrm{~W}_{\mathrm{j}}\right)+ \\
\sum_{\mathrm{L}=1}^{\mathrm{L}} \sum_{\mathrm{k}=1}^{\mathrm{I}} \sum_{\mathrm{j}=1}^{\mathrm{J}}\left(\mathrm{P}_{\mathrm{jk}}^{\mathrm{L}} * \mathrm{Q}_{\mathrm{jk}}^{\mathrm{L}} * \mathrm{~d}_{\mathrm{jk}} * \mathrm{~W}_{\mathrm{j}} * \mathrm{~W}_{\mathrm{k}}\right)
\end{gathered}
$$

(4) state subsidies only related to products and processing, as follows:

$$
\mathrm{N}=\sum_{\mathrm{L}=1}^{\mathrm{L}} \sum_{\mathrm{i}=1}^{\mathrm{I}}\left(\mathrm{B}^{\mathrm{L}} * \mathrm{Q}_{\mathrm{i}}^{\mathrm{L}}\right)
$$

(2) F represents total cost of reverse logistics network; The total goal of reverse logistics network is the minimum total cost, as follows:

Objective function $\operatorname{minF}=\min (\mathrm{G}+\mathrm{U}+\mathrm{Y}-\mathrm{N})$;

Constraint conditions s.t.:

$$
\begin{aligned}
& \mathrm{i} \in\{1,2,3 \ldots \mathrm{I}\} ; \\
& \mathrm{j} \in\{1,2,3 \ldots \mathrm{J}\} ; \\
& \mathrm{k} \in\{1,2,3 \ldots \mathrm{K}\} ; \\
& \mathrm{L} \in\{1,2,3,4,5\} ; \\
& \mathrm{W}_{\mathrm{j}}=0 \text { or } 1 ; \mathrm{W}_{\mathrm{k}}=0 \text { or } 1 ; \\
& 1 \leq \sum \mathrm{W}_{\mathrm{j}} \leq \mathrm{J} ; 1 \leq \sum \mathrm{W}_{\mathrm{k}} \leq \mathrm{K} ; \\
& \quad \mathrm{Q}_{\mathrm{i}}^{\mathrm{L}}, \quad \mathrm{Q}_{\mathrm{ij}}^{\mathrm{L}}, \quad \mathrm{Q}_{\mathrm{jk}}^{\mathrm{L}} \geq 0 ; \\
& \mathrm{Q}_{\mathrm{i}}^{\mathrm{L}}=\sum_{\mathrm{j}=1}^{\mathrm{J}}\left(\mathrm{Q}_{\mathrm{ij}}^{\mathrm{L}} * \mathrm{~W}_{\mathrm{j}}\right) ; \\
& \sum_{\mathrm{i}=1}^{\mathrm{L}}\left(\mathrm{Q}_{\mathrm{ij}}^{\mathrm{L}} * \mathrm{~W}_{\mathrm{j}}\right)=\sum_{\mathrm{k}=1}^{\mathrm{k}}\left(\mathrm{Q}_{\mathrm{jk}}^{\mathrm{L}} * \mathrm{~W}_{\mathrm{k}}\right) ; \\
& \sum_{\mathrm{j}=1}^{\mathrm{J}} \sum_{\mathrm{L}=1}^{\mathrm{L}}\left(\mathrm{Q}_{\mathrm{jk}}^{\mathrm{L}}\right) \leq \mathrm{M}_{\mathrm{K}}^{\mathrm{L}} * \mathrm{~W}_{\mathrm{K}} ;
\end{aligned}
$$

The formula (1) constraint establishes the number of recycling centers and reprocessing centers;

Formula (2) the unit volume of the constraint;

Formula (3) indicates that every reverse logistics network source is transported to various recycling 
centers;

Formula (4) means that each recycling center is transported to each reprocessing center;

Formula (5) constraint maximum processing power.

\section{COLUMN ANALYSIS}

\subsection{Data assumptions}

Suppose to select an area have areas $1,2,3,4,5$, recycling center and processing center in these areas, discarded appliances products mainly include computer, refrigerator, washing machine, air conditioning, the average quality of $5 \mathrm{~kg}$ respectively, $60 \mathrm{~kg}, 35 \mathrm{~kg}, 20 \mathrm{~kg}$, $50 \mathrm{~kg}$. The transportation cost is 0.0015 yuan $/(\mathrm{kg} . \mathrm{Km})$ between the source and recycling centers due to different loading costs, and the transportation cost between the recycling center and the reprocessing center is 0.0014 yuan/(kg. km). The annual scrap amount of major household appliances in the five main appliances, the distance between regions, related expenses and processing capacity, and the national subsidy standard are set respectively. Detailed data are shown in table 1, table 2 , table 3 , and table 4 .

Table 1 Annual s crap of five major household appliance products in each region

\begin{tabular}{c|c|c|c|c|c|c}
\hline \multicolumn{6}{c}{ Annual scrap of five major household appliances in each region (10,000 units) } \\
\hline & computer & Ice box & $\begin{array}{c}\text { Washing } \\
\text { machine }\end{array}$ & Television set & $\begin{array}{c}\text { air } \\
\text { conditioner }\end{array}$ & total \\
\hline A1 & 20 & 18 & 17 & 15 & 10 & 80 \\
\hline A2 & 19 & 17 & 16 & 15 & 11 & 78 \\
\hline A3 & 32 & 26 & 25 & 22 & 20 & 125 \\
\hline A4 & 26 & 23 & 21 & 20 & 19 & 109 \\
\hline A 5 & 28 & 26 & 22 & 22 & 21 & 119 \\
\hline total & 125 & 110 & 101 & 94 & 81 & 512 \\
\hline
\end{tabular}

Table 2 Distance between regions

\begin{tabular}{c|c|c|c|c|c}
\hline \multicolumn{7}{c}{ Distance between regions $(\mathrm{km})$} \\
\hline & A 1 & A2 & A3 & A4 & A5 \\
\hline A 1 & 0 & 81 & 295 & 141 & 165 \\
\hline A 2 & --- & 0 & 226 & 120 & 370 \\
\hline A3 & --- & ---- & 0 & 84 & 144 \\
\hline A 4 & ---- & ---- & ---- & 0 & 390 \\
\hline A5 & ---- & ---- & ---- & ---- & 0 \\
\hline
\end{tabular}

Table.3 Related costs and processing power of reverse logistics network nodes

\begin{tabular}{l|l|l|l}
\hline \multicolumn{4}{c}{ Reverse logistics network node related costs and processing } \\
& $\begin{array}{l}\text { Constructi } \\
\text { on cost } \\
(10,000 \\
\text { yuan) }\end{array}$ & $\begin{array}{l}\text { Operating } \\
\text { expenses } \\
\text { (RMB/Taiwan) }\end{array}$ & $\begin{array}{l}\text { Handling } \\
\text { capacity } \\
(10,000)\end{array}$ \\
\hline $\begin{array}{l}\text { Source } \\
\text { point }\end{array}$ & 0 & 30 & $\infty$ \\
\hline $\begin{array}{l}\text { Recycling } \\
\text { center }\end{array}$ & 300 & 25 & $\infty$ \\
\hline $\begin{array}{l}\text { Recycling } \\
\text { center }\end{array}$ & 5000 & 60 & 300 \\
\hline
\end{tabular}

Table 4 Subsidy standard for recycling of five major waste household appliances in China

Subsidy standard for recycling of five major waste household appliances in China (yuan/Taiwan)

\subsection{Lingo to solve}

Substitution formula simplification model: (1) $\mathrm{G}=\sum_{j=1}^{J}\left(500 * W_{j}\right)+\sum_{k=1}^{k}\left(5000 * W_{k}\right)$;

\begin{tabular}{c|c|l|l|l|l}
\hline & computer & $\begin{array}{l}\text { Ice } \\
\text { box }\end{array}$ & $\begin{array}{l}\text { Washing } \\
\text { machine }\end{array}$ & $\begin{array}{l}\text { Television } \\
\text { set }\end{array}$ & $\begin{array}{l}\text { air } \\
\text { conditioner }\end{array}$ \\
\hline subsidies & 85 & 35 & 80 & 85 & 130 \\
\hline
\end{tabular}

\footnotetext{
(2)U $=\sum_{L=1}^{L} \sum_{i=1}^{I}\left(30 * Q_{i}^{L}\right)+\sum_{L=1}^{L} \sum_{i=1}^{I} \sum_{j=1}^{J}(25 *$ $\left.Q_{i j}^{L} * W_{j}\right)+\sum_{L=1}^{L} \sum_{k=1}^{I} \sum_{j=1}^{J}\left(60 * Q_{j k}^{L} * W_{k}\right)$
} 


$$
\text { (3) } \mathrm{Y}=\quad \sum_{L=1}^{L} \sum_{i=1}^{I} \sum_{j=1}^{J}\left(P_{i J}^{L} * Q_{i j}^{L} * d_{i j} * W_{j}\right)+
$$

$\sum_{L=1}^{L} \sum_{k=1}^{I} \sum_{j=1}^{J}\left(P_{j k}^{L} * Q_{j k}^{L} * d_{j k} * W_{j} * W_{k}\right)$

(4) $\mathrm{N}=425575000 y u a n$;

Because lingo operation scope is limited, the actual process simplifies the calculating data, obtained the approximate solution, results of 0.1611570 e+10 lingo12 generation into the data, then minus the state subsidies of 410750000 yuan, the optimal cost is 1200820000 yuan, need to create a recycling center in 4 locations, at no. 1 and 5 , respectively, set up a processing center.

\subsection{Case summary}

Although the data is hypothetical, it is not difficult to see from the results that the cost of reverse logistics is relatively high, and even if the state has certain subsidies, it still can't solve the problem. This also indirectly verifies the logistics iceberg theory, so the research of reverse logistics construction and optimization is quite meaningful.

\section{CONCLUSIONS}

In this paper, through the understanding of reverse logistics network related content, focus on the scrap electrical appliances product reverse logistics network construction, logistics network optimization model is established, and a lingo to solve, makes every effort to get the optimal reverse logistics cost, logistics decision-making for the enterprise to provide certain theoretical basis and decision-making basis. Of course, there are some deficiencies in this study, such as the time impact and the constraint conditions of the return trip.

\section{ACKNOWLEDGEMENTS}

This research is supported by National Natural Science Foundation of China (Grant No. 71702172), Humanities \& Social Sciences Research Foundation of Ministry of Education of China (Grant No. 15YJC630148), Distinguished Young Teacher Development Foundation of Zhengzhou University (1421326092), and Key Research Foundation of University Education in Henan province (17A520058). The authors would like to thank the editors and anonymous referees for their careful and fruitful comments to improve the quality of this paper.

\section{REFERENCES}

[1] Mengting Wu. 2015. Research status and prospect of reverse logistics network structure design [J]. Logistics technology. 21.pp.15-19.

[2] Xiaobing Xu. 2013. Research status and review of reverse logistics [J]. Logistics technology,07. pp.119-120.

[3] Longqing Liu, Guoqing Zhang. 2013. Research on reverse logistics management [J]. Logistics technology. 06.pp.01-03.

[4] Hongxia Chen, Chao Liu. 2015.Analysis of reverse logistics of home appliance retailers [J]. Management. 4.pp.222-223.

[5] Rajesh Piplani, Ashish Saraswat. 2012.Robust optimization approach to the design of service networks for reverse
logistics[J]. International Journal of Production Research ,5, pp.44-47.

[6] Alessandro Creazza, Fabrizio Dallari, Tommaso Rossi. 2012.Applying an integtated logistics network design and optimization model: The Pirelli Tyre case[J]. International Journal of Production Research, 11. pp.38-40.

[7] $\mathrm{Ji} \mathrm{Hu}, 2014$.Research on the optimization of reverse logistics network of home appliance enterprises [D]Chongqing university of commerce and industry,4. pp.12-17.

[8] Xiaoyong Pan, Jiang Wu, Yong Liu. 2013. Design of reverse logistics network optimization model for waste home appliance recycling [J]. Henan science,10. pp.43-67.

[9] Zhe Luo, Yunli Liu, Youdi Su. 2013. Research on reverse logistics planning of returned goods under low carbon economy [J]. Logistics technology,13. pp.127-129.

[10] Min He, Meiling Deng. 2016. Construction of reverse logistics system for retired household appliance products [J]. Daily appliances,1. pp.45-60.

[11] Lin Liu. 2012. The new method of minimum cost and the implementation of lingo [J]. Journal of pingdingshan college, 5 . pp.03-07. 